\title{
A Study on the Teaching Mode of Flipped Classroom in the New Media Age
}

\author{
Guixin Zhao \\ School of Information, QILU University of Technology, Jinan, China \\ email:guixin79@126.com
}

Keywords: the Flipped Classroom, New Media Age, Teaching Model

\begin{abstract}
The flipped classroom as a modern teaching reforming mode flips the traditional classroom teaching by online and offline flexibility from using the information technology. In essence, the purpose of the flipped classroom is to enhance the quality of teaching in order to promote the development of students. There is a profound analysis of the meaning of the flipped classroom as a popular teaching model in the paper. We analyze the characteristics and the existing problems of the flipped classroom in the new media era. At the same time we gave the development direction of the flipped classroom according with its current problems.
\end{abstract}

\section{Introduction}

After entering the 21st century, the knowledge economy society has become the development direction of all countries in the world. The new demand of talents and science and technology in the knowledge economy society has also led to the new stage of higher education. Higher education has paid more attention to the development of connotation and the improvement of the quality of education ${ }^{[1]}$. The most important of which is the quality of undergraduate education and more the first-class undergraduate teaching is the basic way to achieve this goal ${ }^{[2]}$.

\section{The meaning of the flipped classroom}

In this section we will analyze the meaning of the flipped classroom as a popular teaching model and the characteristics and the existing problems of the flipped classroom in the new media era. At the same time we gave the development direction of the flipped classroom according with its current problems.

\subsection{The Essence of the Flipped Classroom}

There are different understands of the meaning of the flipped classroom as a modern teaching reforming mode, which has the complicated structure. Some scholars believe that the flipped classroom has changed the two links of the knowledge and the knowledge internalization in the teaching process ${ }^{[3]}$. The teaching and internalization is completely subversive. The knowledge imparting and expansion are completed out the class (online) by information technology, however the knowledge of internalization is completed in the class (offline), which forms the flipped classroom. Even with the flipped teaching process, all aspects of classroom learning process will change. Some other scholars believe that the flipped classroom is an adjustment of the time of extracurricular and class ${ }^{[4]}$. The teacher no longer occupies the class time to teach knowledge. Students need to master the knowledge and information in the extracurricular autonomously. The learners can watch the video lectures, podcasts, E-books, etc., and exchange the learning results with other learners at any time. The third point of view is that "teaching video" is the core of the flipped classroom. The flipped classroom is a teaching model in which way the teachers provide teaching video and the learners watch the teaching video in the extracurricular in the information environment ${ }^{[5]}$. The teacher and learning completed the teaching activities by Q \& A, collaborative inquiry and interactive communication ${ }^{[6]}$ in the class. Of course, there are some scholars who 
oppose the teaching video as the core of the flipped classroom, think the video subject can lead to formalization of teaching.

The flipped classroom flips the traditional classroom teaching by online and offline flexibility from using the information technology. But in essence, the purpose of the flipped classroom is to enhance the quality of teaching in order to promote the development of students. It end the learners' passive, receptive learning state in the traditional classroom, transfer the learning options, the right to the learners who can manage their own learning time, and achieve personalized learning and personalized training.

The teachers designed the careful and meticulous teaching links to enable learners to plan their own learning content autonomy based on the project, control the learning rhythm, reflect the unique learning style and knowledge absorption, explore on their initiative, understand and reorganize the knowledge in the flipped classroom. So the learning transfers from the knowledge of the Passive recipients to active explorers.

\subsection{The Characteristics of the Flipped Classroom in the Background of New Media}

The flipped classroom is based on the advent of the new information age, especially the new media era. The education in the new period presents two typical characteristics of informatization (technical change) and democratization (social change). In view of the traditional standardization of classroom teaching is difficult to adapt to social development and the actual requirements of students. There are two contradictions to be solved difficultly in the class teaching system, which is the contradiction between the timeliness of the established teaching teaching rogress and the uneven knowledge of the students and the contradiction between the teachers 'common teaching and the students' individualized cognition. And the two contradictions have become increasingly prominent. The flipped classroom rebuilds the learning process of the traditional classroom "preview classroom teaching - review", transfer as the step of "early learning + self-practice + classroom explanation which improve the propose of the teachers give students the autonomy of learning, enhance the teaching effect, and is a new concept and teaching model in a new era of education and teaching through the use of advanced information technology.

\subsubsection{The Flipped Classroom is more in Line with the Laws of Human Cognition.}

The teachers should not only pay attention to the transmission of knowledge but also focus on the internalization of student knowledge. The teachers are not only the imparter of knowledge, but the construction of student learning. Teachers should ask students to carry out pre-class problemoriented video learning in order to help the students who have different learning background and life experience to build a new diversity understanding through the content of classroom teaching to discuss, targeted puzzled answers and cooperation between peers, students and then so that have On the basis of knowledge and then. That makes the process of dealing with knowledge and conversion of the teaching. Teachers should be guided the students to learn in advance, to find the problem by combining with social reality, and then to think about the method of self-solving the problem or solve the targeted problems which are encountered by the students in the pre-class in the classroom learning, so that make students to apply the knowledge applied to practice and help students dock the knowledge and the practical needs effectivel, improve the students ' learning efficiency, and improve the level of students' master knowledge and skills.

\subsubsection{The flipped classroom is a teaching model based on large data non-linear learning.}

The flipped classroom has the characteristics of governance in the teaching subject. Participants not only are teachers and students, but also countries, society and other groups. Diversified entities consult dynamically and influence each other mutually though the information technology platform.

1、 Teachers are no longer the only source of knowledge. The form of multi-subject knowledge system gradually promotes the digestion of the authority of the teaching, so that the democracy and equality in the main body can be truly realized. 
2、 Teaching resources reflect the sharing characteristics. Different from the traditional teaching resources, the teaching resources of the flipped classroom are mainly divided into two categories: information resources and material resources, which are distributed inside and outside the classroom. Among them, the information resources supported by the basic data are easy to store, have the dynamic and sustainable characteristics of been multiple used, easy communicated and modified according to different students real-time, and more this trend will help promote the equalization of social education resources.

3、 The teaching-carriers have the three - dimensional characteristics. The flipped classroom teaching can use the video, pictures, online community and other rich network of educational resources to eliminate space-time barriers and achieve efficient, three-dimensional learning relying on advanced educational technology.

4、 The education process is flexible. The students, the teachers, the teaching content, the teaching methods, the teaching media and the teaching environment and other factors influence the teaching effect.

The flipped classroom based on the large data thinking non-linear learning has the characteristics of debris, the diversity of learning space, the discourse of learning content, the procrastination of information transmission and the initiative of knowledge construction. It does not rigidly adhere to the strict norms of the traditional classroom. It accords with the principle of "self-learning, cooperative learning and inquiry learning," in the study of the main status, learning time, learning space, learning and other aspects to select and, design the teaching process flexibly, as much as possible to make the classroom teaching the best function, and reflect the largest value. At the same time, the flipped classroom based on the modern information technology can also form a large data of teaching behavior. We can use the appropriate data mining technology to analyze the behavioral characteristics of "teaching" and "learning" in the flipped classroom and its influencing factors. That can help to sum up the advantages and disadvantages the flipped classroom, clear the workcenter of gravity and the development of ideas and implement accurately.

\subsubsection{The Flipped Classroom Helps to Build a New Teacher-student Relationship.}

The flipped classroom makes the teacher and student roles to flip, especially the flip of the teaching purpose "to stimulate students' learning potential". In the flipped classroom, all the teaching work around the "student-center" to carry out, students have a more free and independent choice, you can choose their own learning time, learning places, learning fragments, free to think and practice, select and build their own learning community for interaction, collaboration and innovation, communicate with teachers for puzzled problems in the classroom to in the classroom, and applied the knowledge and skills you have learned to practice after school. In the pre - class self - study stage, the student is the recipient of the information and the discoverer of the problem, the teacher is the assignor of the learning task, the designer and producer of the microculture learning resource. In the internalization stage in the class, the student is the active constructor of the knowledge and the expert of problems. the teacher is the organizer of the classroom teaching, the guide, the person who can solve the puzzles, and the Subject expert. In the sublimation stage after school, the student is the active application practitioner, is the innovator; the teacher is the helper and the appraiser. Students transfer from the passive recipients into active explorers in the learning process, teaching are from the inculcation to the interaction, teaching and learning improve each other, teachers and students benefit each other, truly reflects the return of the study to "learn to use".

\subsection{The Real Challenges Faced by the Flipped Classroom}

As a new thing and the teaching Reform Mode in Colleges and Universities, the flipped classroom has changed the traditional teaching methods, but neglected the traditional ideas rooted in the heart. We see the "lively" "active" classroom but the students grasp the knowledge less than expected; we create a personalized learning environment for students, but ignored the difference 
between the learning ability between each other. There are several aspects of the challenges in the course of the use of the flipped classroom.

\subsubsection{Classroom Formalization}

The flipped classroom is a teaching methods using of multimedia and network technology, through personalized education to cultivate the autonomy and the spirit to explore initiatively of learners, and form the open knowledge and then cultivate the innovative ability. The flipped classroom highlights the learner's dominant position, mobilize the learner's sensory system through the use of multimedia technology and other external means, produce the cognitive conflict of learners, stimulate the learning motivation and cultivate the independent learning habits. But the flipped classroom is not only reflected in the presence of multimedia technology, whether the autonomy of domination, whether the relationship changes between teaching main subject. In the teaching practice, some of the teachings have the understanding bias on the core of the "flip classroom". They think that the flipped classroom is "video technology + classroom discussion + dominate the time". The teaching staffs were placed outside the teaching activities. The teaching relationship was simple inverted. The flipped classroom was turned into a "let go of the classroom". The class discussion was turned into a lively discussion. That was away from the original theme of the flip classroom resulting in classroom teaching formalization and vulgarization.

The external features of the flipped classroom are indeed to achieve cognitive, learning ways to share and make the classroom full of vitality through the classroom discussion. But in the essence, the flipped classroom is to cultivate learners self-learning habits and learning ability, mobilize individual actors to take the initiative to learn, free explore and weak the academic authority. The results of the practice of the flipped classroom showed that some students gave the relatively low classroom learning evaluation and Self-evaluation. Students thought there is not much opportunity to discuss in the flipped classroom and almost no valuable speech. That did not achieve the desired teaching effect.

\subsubsection{Knowledge is fragmented}

The fragmentation of knowledge refers to the process in which the holistic and systematic knowledge system is divided into no logic multiple pieces of knowledge. The fragmentation of knowledge has the infinite possibilities of dismantling, reorganizing and constructing, so the fragmented knowledge helps to deconstruct the conventional thinking and promote innovative thinking at a certain extent. But the disorder and lack of internal logic knowledge fragments is not conducive to construct the learner's knowledge system, reduce the ability of knowledge migration and recycling capabilities. In the flipped classroom teaching, the knowledge presents though the "short and pithy" video or PPT, lesson plans and other forms .The knowledge reflected by video is lack of systematic. And the learners can arbitrarily interception of knowledge fragments to learn, ignore the integrity and continuity of the knowledge. That exacerbated the degree of knowledge fragmentation. Asynchronous interaction, especially the lag of the problem affects students' understanding of the problem at a certain extent, leads students to "knowledge fault" and affect the integrity of knowledge. The pre-lesson video learning can not achieve the real-time interaction with students face to face.

\subsubsection{Development of polarization Subsection}

The essence of the flip classroom is to cultivate the initiative spirit to explore, to achieve personalized learning and growth. But in the study the learner have the differences in learning methods, learning ability et al, invest different learning time. So the progress of learning, learning effect is very different, and was polarized development. A number of studies have shown that the teaching effect of the flipped classroom is closely related to the students 'autonomous learning ability, is positively correlated with the students' basic knowledge and autonomous learning ability. The high level learners have a strong ability to self-learning, are more suitable for the teaching 
mode of the flipped classroom. For students who have the relatively weak base, especially the students with weak self-learning ability, the traditional teaching model is still an effective means of quickly transferring knowledge.

\subsection{The development direction of the flipped classroom}

The flipped classroom is not just a teaching model, it also shows a kind of educational philosophy adapted to the contemporary society development. According to the problems in the concrete implementation process, the paper analyzes the main future development direction of the flipped classroom in our country.

\subsubsection{Establish the correct value orientation}

Please The classroom is not a simple steps of adjustment of class under the class, online and offline learning, nor is the synonymous with information technology teaching, but the traditional classroom subversion and new design, to enhance learners learning ability, is the essential means to achieve personalized teaching and a complete change in the concept of traditional backward education. In the classroom teaching practice, we must establish the "student-center" conception and change the teaching for the construction of the constructor. In the interaction of, we must activate the learners' motivation and mobilize the individual action. The essence of teaching is the flow between the information and the subject. The interactions between students and students, teachers and students, as well as between teachers and students and teaching media directly affect the teaching effect.

\subsubsection{Build the system of point, line and surface}

In view of the fact that the flipped classroom can easily lead to the fragmentation of knowledge, we should follow the inherent structure of knowledge and the law of knowledge transmission in teaching practice, construct a modular, systematic, operational and easy-to-extract knowledge system to realize the one-dimensional knowledge combination from "point" to "line", the twodimensional knowledge structure from "line" to "surface" and the three-dimensional knowledge system from the" surface "to" body ". We should break the traditional discipline of internal cooperation inertia, and actively look for possibility cooperated with other departments, prompt that the teachers are not confined to the traditional "academic tribe", go out of the original disciplines, seek more cooperation, and become a compound teaching talent through self education.

\subsubsection{Enhance the Diversity of Quality Evaluation}

The traditional standardized test can quantify the students' learning performance in an intuitive way, but this kind of evaluation method only stay in the memory of the concept of knowledge and abstract use level, can not fully assess the teaching state and learning effect of the students in the flipped classroom. The evaluation methods have some limitations. The practical evaluation of the flipped classroom has considerable complexity. How to develop a set of suitable measurement tools and the scientific evaluation system is a question that is worthy of attention and research in classroom teaching practice.

\section{Conclusions}

Compared with the traditional teaching, the flipped classroom has the more advantageous than the traditional teaching that it can not surmount itself. It can more rationally allocate the teaching time of teachers and students, and accord more with the cognitive law of human beings. The teaching effect is better than the traditional teaching. This is also the trend of the development of education in the new media era. We should build the flipped classroom teaching system in accordance with China's national conditions, which can meet the education system in China, 
stimulate students to learn interest, achieve students' Self-learning and cooperative-learning and cultivate students' creative thinking, high level of reasoning and other critical thinking ability to become an international competitive talents.

\section{Acknowledgements}

In this paper, the research was sponsored by the teaching research project of QiLu University of Technology (Project No. 2015024).

\section{References}

[1] Gerald C Cannod, Janet E Burge, Michael T Helmick. Using the Inverted Classroom to each software Engineering [R]. USA: Miam University Technical Reports:2007.

[2] Jeremy F Strayer.How Learning in an Inverted classroom influences cooperation, innovation an task orientation [J]. Learning Environments Reasearch,2012(15):171-193.

[3]DAWSON L A P. Motivation and cognitive load in the flipped classroom: Definition, rationale and a call for research [J]. Higher education research \&development, 2015,34(1):1-14.

[4]DELOZIE S J, RRHODES M G. Flipped classrooms: A review of key ideas and recommendations for practice [J]. Educational psychology review, 2016:1-11.

[5] YONG D, LEVY R, LAPE N. Why no difference? A controlled flipped classroom study for an introductory differential equations course [J]. Primus problems resources \& issues in mathematics undergraduate studies, 2015,25(9-10):907-921.

[6] ROWLEY N, GREEN J. Just-in-time teaching and peer instruction in the flipped classroom to enhance student learning [J].Education in practice, 2015,2(1):14-17. 